\title{
Aortic arch repair with frozen elephant trunk versus conventional elephant trunk
}

\author{
Davut Cekmecelioglu ${ }^{1,2,3}$, Joseph S. Coselli ${ }^{1,2,3,4}$ \\ ${ }^{1}$ Department of Cardiovascular Surgery, Texas Heart Institute, Houston, Texas, USA; ${ }^{2}$ Division of Cardiothoracic Surgery, Michael E. DeBakey \\ Department of Surgery, Baylor College of Medicine, Houston, Texas, USA; ${ }^{3}$ Department of Cardiovascular Surgery, CHI St Luke's Health-Baylor \\ St Luke's Medical Center, Houston, TX, USA; ${ }^{4}$ Cardiovascular Research Institute, Baylor College of Medicine, Houston, TX, USA \\ Correspondence to: Joseph S. Coselli. Division of Cardiothoracic Surgery, Michael E. DeBakey Department of Surgery, One Baylor Plaza, BCM 390, \\ Houston, TX 77030, USA. Email: jcoselli@bcm.edu.
}

Submitted Dec 17, 2019. Accepted for publication Jan 28, 2020.

doi: 10.21037/acs.2020.02.11

View this article at: http://dx.doi.org/10.21037/acs.2020.02.11

\section{Introduction}

Conventional and frozen elephant trunk procedures represent two distinct approaches to the surgical treatment of thoracic aortic aneurysm and dissection. The conventional elephant trunk (cET), introduced almost four decades ago by Hans Borst (1), facilitates a two-stage open technique for the surgical treatment of disease affecting both the aortic arch and the distal aorta (i.e., descending thoracic and thoraco-abdominal aorta) and represents an evolutionary leap in the treatment of these complex diseases. The frozen elephant trunk (FET) is a newer, hybrid technique combining open and endovascular repair. It is typically performed in a single stage to replace the aortic arch and repair the proximal portion of the descending thoracic aorta; subsequently, repair can be extended distally with additional open or endovascular repair. Despite the widespread adoption of the FET approach, the evidence is ambiguous regarding the value of FET repair for treating distal aortic pathologies, and there is still a role for the 'scientific dialectic,' particularly in terms of long-term results.

In cET, a simple, free-floating extension (or "trunk") of the replacement graft tube is suspended in the descending thoracic aorta during open total aortic arch repair. During the second stage of a cET repair, the trunk initially serves as the proximal clamp site, which obviates the need to directly clamp the distal segment of the aortic arch. This reduces the time and effort required to initiate repair, thereby reducing the risk of injury to nearby nerve, bronchial and lymphatic structures. As repair progresses, the trunk is anastomosed to the distal aortic replacement graft. Although single-center reports describe excellent early results with cET $(2,3)$, the mortality rate between the first and second operations is not negligible.

The expected advantages of FET are that it can be performed in a single stage and that it creates an optimal proximal landing zone for subsequent thoracic endovascular repair of the remaining descending thoracic aorta. Because the endovascular portion of an FET device is directly sutured to the open replacement graft by the manufacturer, there is little chance of device migration. Evidence suggests that FET, when used to treat acute aortic dissection, reduces distal aortic malperfusion, facilitates thrombosis of the false lumen, aids remodeling, and may reduce the risk of distal aneurysm growth and improve long-term survival $(2,4)$.

The FET prostheses used in Europe and elsewhere are not yet approved for use in the United States; to overcome this obstacle, several modified FET approaches have been developed. During a conventional total aortic arch replacement with an ET extension, we use a skirted graft, in combination with a stent-graft inserted antegrade under direct vision, in order to perform a modified, singlestage FET procedure; commonly, the stent-graft is then incorporated into the distal suture line, or if the left subclavian artery is too distal, two or three sutures are used to secure it in place (5).

Comparing the cET and FET techniques is challenging because of variations in study periods, indications, patient risk profiles, surgeon experience, and the lack of randomized 
controlled trials. The cET tends to be used in patients who have extensive distal aortic disease (i.e., degenerative aneurysm or dilation of chronic dissection). The FET has been frequently used in patients with acute DeBakey type I aortic dissection, in order to extend repair into the distal arch and the proximal portion of the descending thoracic aorta, which is typically of normal diameter. Although a position paper on FET has been published (6), few guidelines exist.

\section{Falsifiability and surgical evolution}

In cET, the development of postoperative paraplegia is exceedingly rare. Early on, spinal cord injury was identified as a potential concern of the FET approach, with reported rates as high as $22-24 \%(7,8)$. The likelihood that FET poses an elevated risk of paraplegia remains this technique's main drawback. Additionally, reports of FET describe a wide range of outcomes regarding mortality and stroke rates $(2,6,8)$. For example, according to a recent position paper by the Vascular Domain of the European Association of Cardiothoracic Surgery, reported rates of in-hospital mortality range vastly, from $1.8 \%$ to $17.2 \%$ (6).

A meta-analysis by Preventza et al. (8) reported data for 3,145 patients from 35 studies, with a focus on mortality and neurological events associated with FET procedures. The pooled rate of overall mortality was $8.8 \%$. Similarly, a $7.7 \%$ mortality rate was reported for FET, as described by a recent systematic review of 12 comparator observational studies, which was less than the $14.5 \%$ rate determined for cET procedures (2). Preventza and colleagues (8) reported a pooled stroke rate of $7.6 \%$. Again, this rate is similar to that reported by the comparator meta-analysis, which found no difference between FET and cET repair in associated stroke rate (6.5\% vs. 9.7\%) (2).

Karl Popper's famous doctrine, "In so far as a scientific statement speaks about reality, it must be falsifiable; and in so far as it is not falsifiable, it does not speak about reality" (9), seems valid and applicable to the evolution of surgical techniques. Discourse and falsifiability should be considered the underpinnings of surgical science.

E. Stanley Crawford was arguably the most dominant aortic surgeon of the 1970s, 80s, and early 90s before his untimely death in 1992. Borst, reflecting on his own eponymous ground-breaking introduction of the cET, stated, "The bright future of the elephant trunk technique could not be anticipated at that time. Stanley Crawford, the most experienced surgeon in the treatment of aortic pathology at that time, was quite skeptical when I first explained the elephant trunk technique to him" (1). Despite his initial skepticism, Crawford soon adopted a modified version of Borst's cET; the value of discourse aimed at falsifiability aided its evolution. A short time later, Crawford et al. (10) reported their extensive results, emphasizing the place of the ET operation in aortic surgery. In contemporary practice, we have modified our approach to FET extension by performing open (rather than further endovascular) distal aortic repair-the stentgraft portion of the original FET repair is trimmed and directly anastomosed to the replacement graft. The spirit of these pioneering surgeons lingers, suggesting that there is probably no method that could not be further improved.

\section{Acknowledgments}

Stephen N. Palmer, PhD, ELS, and Susan Y. Green, MPH, contributed to the editing of the manuscript.

\section{Footnote}

Conflicts of Interest: The authors have no conflicts of interest to declare.

Open Access Statement: This is an Open Access article distributed in accordance with the Creative Commons Attribution-NonCommercial-NoDerivs 4.0 International License (CC BY-NC-ND 4.0), which permits the noncommercial replication and distribution of the article with the strict proviso that no changes or edits are made and the original work is properly cited (including links to both the formal publication through the relevant DOI and the license). See: https://creativecommons.org/licenses/by-nc-nd/4.0/.

\section{References}

1. Borst HG. The birth of the elephant trunk technique. J Thorac Cardiovasc Surg 2013;145:44.

2. Hanif H, Dubois L, Ouzounian M, et al. Aortic arch reconstructive surgery with conventional techniques vs frozen elephant trunk: A systematic review and metaanalysis. Can J Cardiol 2018;34:262-73.

3. LeMaire SA, Carter SA, Coselli JS. The elephant trunk technique for staged repair of complex aneurysms of the entire thoracic aorta. Ann Thorac Surg 2006;81:1561-9; discussion 1569.

4. Akbulut M, Ak A, Arslan Ö, et al. Early and mid-term 
results of frozen elephant trunk procedure for acute type A aortic dissection. Turk Gogus Kalp Damar Cerrahisi Derg 2019;27:135-42.

5. Preventza O, Coselli JS, Mayor J, et al. The stent is not to blame: Lessons learned with a simplified US version of the frozen elephant trunk. Ann Thorac Surg 2017;104:1456-63.

6. Shrestha M, Bachet J, Bavaria J, et al. Current status and recommendations for use of the frozen elephant trunk technique: a position paper by the Vascular Domain of EACTS. Eur J Cardiothorac Surg 2015;47:759-69.

7. Tian DH, Wan B, Di Eusanio M, et al. A systematic review and meta-analysis on the safety and efficacy of the frozen elephant trunk technique in aortic arch surgery.

Cite this article as: Cekmecelioglu D, Coselli JS. Aortic arch repair with frozen elephant trunk versus conventional elephant trunk. Ann Cardiothorac Surg 2020;9(3):223-225. doi: 10.21037/acs.2020.02.11
Ann Cardiothorac Surg 2013;2:581-91.

8. Preventza O, Liao JL, Olive JK, et al. Neurologic complications after the frozen elephant trunk procedure: A meta-analysis of more than 3000 patients. J Thorac Cardiovasc Surg 2019. [Epub ahead of print].

9. Stamos DN. Popper, falsifiability, and evolutionary biology. Biol Philos 1996;11:161-91.

10. Crawford ES, Coselli JS, Svensson LG, et al. Diffuse aneurysmal disease (chronic aortic dissection, Marfan, and mega aorta syndromes) and multiple aneurysm. Treatment by subtotal and total aortic replacement emphasizing the elephant trunk operation. Ann Surg 1990;211:521-37. 